\title{
EVIDENCIAS MÉDICO ANTROPOLÓGICAS SOBRE EL ORIGEN DEL PISHTACO
}

\begin{abstract}
Rosario de Pribyl $\left.\right|^{1, a}$
\section{Resumen}

A través de un análisis médico-antropológico, se otorga en el presente artículo, una interpretación científica respecto a la creencia sobre el pishtaco en el Perú. Se expone y analiza evidencias históricas, farmacéuticas y antropológicas sobre el uso de material del cuerpo humano con fines médicos en Perú y Europa. Podemos ubicar el antecedente de este fenómeno en la Europa del siglo XVI y XVII: el pishtaco no tiene un origen andino. La metodología utilizada y los hallazgos principales otorgan una perspectiva de trabajo alternativa al análisis etnológico y antropológico convencional, a ejemplo del análisis de la figura del pishtaco. Los profesionales que trabajan en el ámbito de la salud intercultural pueden contar de esta manera con herramientas científicas que les permitan identificar de manera eficiente las creencias de los pobladores y las comunidades nativas respecto al cuerpo, la salud y los sistemas médicos, en su contexto históricocultural correspondiente.
\end{abstract}

Palabras clave: Antropología; Historia de la Medicina; Farmacología; Cirugía; Perú; Europa (fuente: DeCS BIREME).

\section{MEDICAL ANTHROPOLOGY EVIDENCES ON THE PISHTACO ORIGIN}

\begin{abstract}
This paper will contribute to the scientific development of a new approach on the pishtaco in Peru by means of medical anthropological analysis. The model emphasizes presentation and analysis of historical, pharmaceutical, and anthropological evidence supporting use of human tissues with specific medical goals in Peruvian and European regions. We can find the origin of this phenomenon around the sixteen and seventeen centuries in Europe: The pishtaco has no an Andean origin. The methodology and main conclusions of this paper could provide to the scientific community an alternative perspective to the conventional anthropological and ethnological research, as an example of a medical anthropological analysis of the pishtaco character. Professionals involved in intercultural health projects could have a new insight on this issue thanks to these results. They will obtain an adequate historical-cultural context for the interpretation and understanding of people and native communities' beliefs about health, body and medical systems.
\end{abstract}

Key words: Anthropology; History of Medicine; Religion and Medicine; Surgery; Peru; Europe (source: MesH NLM).

\section{INTRODUCCIÓN}

La figura del pishtaco en el Perú ha sido objeto de interés para la investigación etnológica, antropológica y sociológica. Para la mayoría de investigadores el pishtaco constituye una creencia de raigambre panandina de origen precolonial.

En publicaciones basadas en trabajos de campo en el contexto peruano ${ }^{(1,2)}$ se le suele vincular directamente con la figura del degollador (Figura 1) en la cultura Moche y a las prácticas de sacrificio ritual de humanos antes y durante la insurgencia del imperio incaico ${ }^{(3,4)}$. Versiones más recientes ${ }^{(5,6)}$ vinculan su presencia con el malestar y sozobra de la población en tiempos de crisis, como una respuesta de resistencia cultural y social frente al dominador blanco, los consorcios petroleros y de minas, el aparato político-militar del estado o el accionar de grupos armados insurgentes en el país.

Lo que todos los investigadores tienen en común es aseverar la existencia del pishtaco en función a una línea histórica cuyo origen ubican en las culturas autóctonas del Perú. Si los relatos presentan diferencias sustanciales las atribuyen a procesos sociales y políticos locales o a prácticas culturales propias de cada una de las regiones donde estos han sido registrados.

El pishtaco se ha posicionado dentro del imaginario popular como una creencia de índole sumamente heterodoxa para corrobar estas tesis. La interpretación de los elementos, asociaciones, características y

\footnotetext{
1 Facultad de Antropología Social y Cultural, Universidad de Viena. Viena, Austria.

a Psicóloga y psicoterapeuta especialista en Terapia Sistémica y Psiconeuroinmunología. Candidata al doctorado en el área de Etnomedicina y Antropología Médica.
}

Recibido: 24-01-10 Aprobado: 17-03-10 


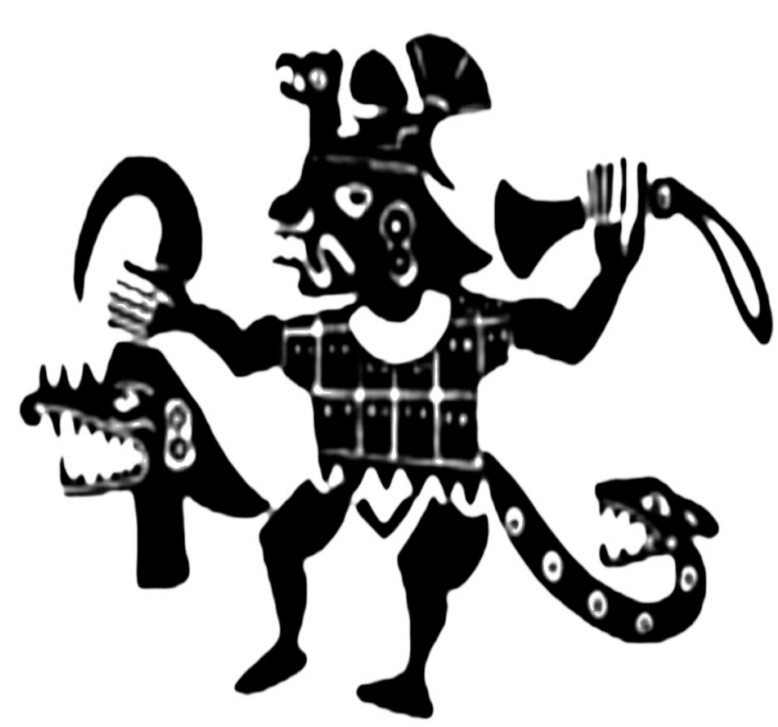

Figura 1. Ai Apaec, Dios de los Moche (300 a.c. - 600 d.c.). Reina sobre la vida y la muerte, los animales, las plantas y el hombre. El sacerdote decapitaba a las víctimas, en su mayoría prisioneros de guerra, a modo de ofrenda. Es también conocido como "el degollador". Foto: Museo de Arqueología, Antropología e Historia de la Universidad Nacional de Trujillo, Perú.

actuar del pistacho encontrados en la literatura, no han otorgado de manera sustancial la necesaria evidencia científica que corrobore la existencia de este personaje en la historia de las culturas americanas en una época anterior al contacto con España. Encontramos en los distintos relatos asociados con el pistacho, que los elementos centrales y comunes a este personaje son de origen exclusivamente europeo, como demostraremos más adelante.

Una lectura cuidadosa del origen del pishtaco aporta una comprensión adicional para entender las concepciones de gran parte de la población peruana con relación a la salud, la enfermedad, el cuerpo y la muerte. Ello nos permite acceder a una dimensión interpretativa nueva, a través de la cual la oficialidad y los responsables de las políticas de salud pública podrían encontrar nuevas formas en la valoración e interpretación de las creencias y actitudes de los usuarios de los servicios de salud en el país.

La dinámica social alrededor de este personaje nos permite explicar relaciones de subalternización, dependencia y violencia en las relaciones médicopaciente, en una figura paralela a la dicotomía europeoindígena o citadino-rural. Un análisis alternativo de esta creencia contribuye sustancialmente a comprender el proceso de convivencia de tradiciones en el contexto del pluralismo médico del país junto con sus problemas y desafíos pasados y actuales. El pishtaco pone al descubierto el proceso de imposición y posterior asimilación cultural de modelos europeos de atención médica de la época.

El modo en que se posiciona, valora y comercializa el cuerpo humano dentro de estos discursos constituyó uno de los retos epistemológicos, ideológicos y religiosos más difíciles con los que se enfrentó el poblador andino al entrar en contacto con el mundo y cosmovisión europeos. La tarea principal impuesta por la corona española consistió en el aprovechamiento y extracción de recursos naturales y metales preciosos, sin presencia en la agenda política de espacio alguno para cualquier forma de diálogo cultural que permitiera una explicación del proceder de los hispanos. Los aspectos y conocimientos médicos no fueron ajenos a esta carencia inicial.

La importancia de una reorientación del enfoque convencional en el análisis de determinadas creencias populares, rurales y urbanas, tiene un valor teórico y práctico de suma importancia para el trabajo en salud comunitaria e intercultural. Una comprensión de estas creencias y su origen real por parte del personal de salud y los gestores de proyectos en esa línea puede tener como beneficio un cambio de actitud frente al poblador.

\section{TRAS LAS HUELLAS DEL PISHTACO}

El pishtaco o pistaco, también conocido como ñak'aj o ñak'aq en el sur andino, pishtako o pishtaku en el centro de los andes y karikari, karisiri o llik'ichiri en la zona aymara del altiplano de Perú y Bolivia, es uno de aquellos personajes fatídicos del imaginario popular que goza de impresionante representatividad entre los distintos grupos culturales, sociales y étnicos en el Perú.

La palabra quechua pishtac significa "cortar en tiras o en trozos": El pishtaco mata a sus víctimas a fin de extraerles la grasa para venderla a terceros o utilizarla con fines medicinales, industriales o técnicos.

En los escritos más tempranos sobre el tema que datan del siglo XVI se encuentra al personaje del pishtaco con una fisionomía decididamente europea ${ }^{(7,8)}$. En un relato sobre el movimiento del Taki Onqoy (rebelión social iniciada en 1575 contra el invasor español y especialmente contra la iglesia católica) señala Cristóbal de Molina que: Los indios tenían la creencia que los españoles habían sido enviados a este reino para recolectar la grasa de los indios y curar una enfermedad para la cual no existía otra cura que ésta ${ }^{(8)}$. 
En el siglo XVII misioneros betthlemitas, miembros de la única orden que se fundó y extinguió en América, fueron asesinados en el Cusco, por sospechar que ellos mataban a los indígenas y los enterraban bajo las esquinas de la iglesia del Cusco, de modo que ésta sea más robusta: A los indios del Cuzco les hizo creer algún bellaco que los bethlemitas degollaban a los enfermos para sacarles las enjundias y hacer manteca para las boticas de Su Majestad (sic). Así, cuando encontraban en la calle a un belethmita, le gritaban ¡Naca! ¡Naca! (degolladores o verdugos)... (9). Otra versión del hecho sugiere que un sacerdote de la misma orden fue asesinado en Ichu (Puno) debido a que Muchas personas habian desparecido de la comunidad, ellos fueron robados por el Padre que, luego de degollarlos, les extraía la grasa de sus cuerpos ${ }^{(4)}$. Durante la época colonial y el virreinato el pishtaco ha sido identificado como un colonizador de piel blanca que asalta principalmente a indios que se encuentran solos en un camino aislado o solitario. El pishtaco es un monje español que durante el día catequiza y en la noche extrae la grasa de los nativos para Curar las llagas de los castellanos ${ }^{(1)}$.

El pishtaco de aquél entonces, pertenece a alguna orden religiosa encargada de atender enfermos o catequizar. Suele ser también un miembro de la nobleza, una autoridad local española, un hacendado o colono poderoso. Es él quien envía, entrena y mantiene al pishtaco dentro de la cadena de producción de grasa humana y le concede un carácter de intocable, incluso en aquellos casos en los que ha sido denunciado a las autoridades. El pishtaco goza pues de impunidad.

Las fuentes encontradas en el siglo $X X$ brindan las primeras características del pishtaco basadas en encuestas y entrevistas a pobladores de Cuzco, Apurímac y Ayacucho ${ }^{(5)}$.

Las creencias con relación al pishtaco no han sido ajenas al hombre europeo. En 1786 un grupo de enajenados pobladores lincharon a médicos y personal de salud del Hospital de Pobres de Lyon (Francia), por el rumor que en el hospital se mataba a niños y pobres para vender su cuerpo a los ricos. En 1880 agricultores de la región de Estiria (Austria) aseguraban que en el Hospital de los Hermanos de la Misericordia de Graz, Krankenhaus der Barmherzigen Brüder, los médicos tenían la dispensa especial o privilegio de matar a una persona una vez al año, durante la pascua, para preparar medicamentos con él (10).

A partir de la época republicana hasta mediados de la década de 1970 en el Perú, la imagen del pishtaco ha variado al punto de incluir personajes netamente mestizos, incluidos miembros de la propia comunidad, quienes servían de ayudantes al pishtaco. A partir de la década de 1950 surgen otros escritos que toman información de poblados más remotos, donde la figura del pishtaco cobra otras características. Si se trata de un personaje mestizo, es un autóctono que ha abandonado, debido a su estilo de vida o actividad laboral, su lengua y costumbres de origen ${ }^{(11)}$. Existen relatos en los cuales, pobladores organizados han victimado a dichos mestizos al sospechar que se trataban de pishtacos Porno conocer la lengua de la comunidad ${ }^{(5)}$. Estos pishtacos modernos se encuentran inclusive organizados en asociaciones o clubes o son empleados secretos del gobierno ${ }^{(4)}$.

El pishtaco sintetiza ahora elementos hispanos y andinos, deja de pertenecer a las tradicionales clases explotadoras del país para llegar a la ciudad y a las comunidades de la amazonía. Los elementos que utiliza se han vuelto más sofisticados: usa un auto o jeep, en vez de andar a caballo; detecta a sus víctimas con ayuda de aparatos electrónicos ${ }^{(6)}$ o utiliza amplias redes para el tráfico de la grasa humana, incluida, entre ellas, la modalidad del tráfico de órganos ${ }^{(3)}$. El perfil de la víctima ha variado también en forma notable. El pishtaco inclusive habla con sus víctimas o se presenta como un viajero en busca de posada y abrigo ${ }^{(4)}$. A partir de la década de 1980, a consecuencia de la oleada sangrienta que sufrió el país por el accionar del grupo maoísta Sendero Luminoso, se han incluído entre sus víctimas a niños, ancianos y mujeres. El pishtaco lleva ahora pistolas, metralletas, armas sofisticadas y uniforme. Pero curiosamente, sigue asesinando a sus víctimas con un cuchillo.

La indefensión que experimentaban sus víctimas en el pasado colonial también ha experimentado un cambio sustancial. A inicios de 1920 se observa una suerte de inversión de roles donde el pishtaco es asesinado y las víctimas son liberadas con ayuda de elementos o seres de la naturaleza (lluvia, animales), de la vida cotidiana o por el simple azar ${ }^{(4)}$. Las víctimas logran embaucar o distraer al asesino, final feliz que no suele encontrarse en las historias de pishtacos recogidas en otras regiones en períodos similares.

No existen estudios sistemáticos sobre la relación entre la aparición de los pishtacos y períodos específicos del ciclo agrícola en la región andina. Se ha mencionado su aparición en el tiempo de la cosecha, alrededor del mes de abril, y con frecuencia durante la época de sequía en el mes de agosto ${ }^{(5)}$. Es plausible señalar una vinculación entre la sozobra del poblador andino ante la inminente ausencia de cosecha en estos meses y los ataques del pishtaco ${ }^{(12)}$. En este contexto, la aparición del pishtaco precede una situación de carestía entre los pobladores, así como una posibilidad de revertir la situación a través 
de ofrendas en el contexto de rituales durante la cosecha y sequía. Cabe señalar que en la mayoría de situaciones de ataque adscritas al pishtaco, este no suele aceptar un trueque $u$ ofrenda a cambio de liberar a su prisionero ${ }^{(3)}$. Es clara también la asociación del pishtaco con fiestas y fechas especiales en el calendario cristiano católico, como el identificar el Día de San Bartolomé, el 24 de agosto, como el día del pishtaco (Figura 2).

Molinié menciona al pishtaco como un Peligroso intermediario entre el mundo blanco y la comunidad indígena (11). Si precisamos estas relaciones en el contexto peruano, encontramos una asimetría directa entre las relaciones de producción en manos del sistema occidental (blancos, poder, invulnerabilidad) y las fuerzas productivas (indios, dependencia/explotación, vulneración de sus derechos).

Ansión menciona que los relatos muestran una clara relación de intercambio comercial entre el nak'aq, los ricos de la ciudad y el extranjero: Esto es aun más

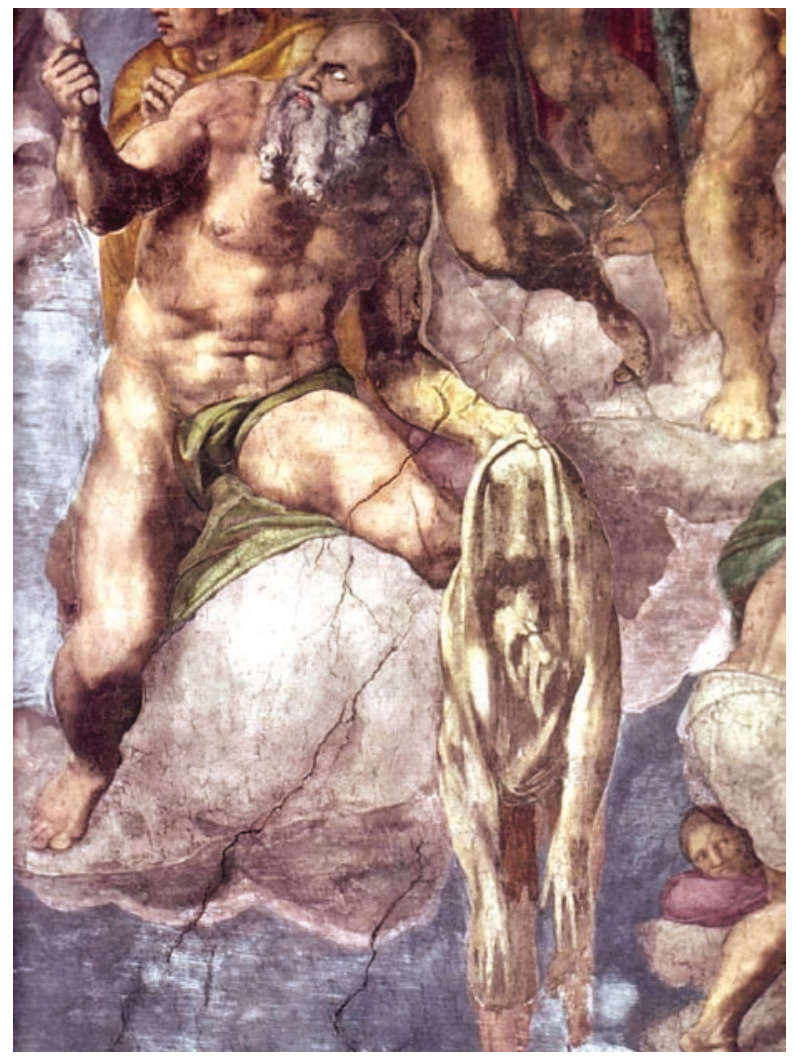

Figura 2. San Bartolomé. Apóstol de Jesús que fue desollado vivo por orden del rey armeno Astiages. Se le representa con un gran cuchillo y llevando su piel sobre el brazo, a modo de prenda. Es patrón de los curtidores y de quienes trabajan con pieles, y santo que cura epilepsias, convulsiones y trastornos nerviosos en general. Detalle del fresco El Juicio Final (1541) de Miguel Ángel en la Capilla Sixtina en Roma (Italia) representando a San Bartolomé sosteniendo su piel. Foto Internet. claro en los casos en que el nak'aq es un hacendado. La multiplicidad de versiones se explica entonces en relación con las realidades locales diversas, pero todas tienden a explicar la situación de explotación ${ }^{(3)}$. El pishtaco "aparece" en forma crítica, cuando la tecnología o el modo de vivir foráneo se acerca de modo irreversible y acelerado a la comunidad y cuando esta es sometida a presión externa, ya sea por el estado, la iglesia, grupos armados o corporaciones mineras ${ }^{(6)}$.

\section{EVIDENCIAS SOBRE EL CARÁCTER MÉDICO DEL PISHTACO}

Una de las tesis que nos motivó a escribir este artículo es la impresionante destreza quirúrgica con la que actúa el pishtaco. Sorprenden la exactitud con que realiza el proceso de extirpación de grasa y la manera en que disecciona a sus víctimas. No puede tratarse de un delincuente común, tiene que poseer necesariamente conocimientos de anatomía humana y experiencia en ello.

Pese a la extensa bibliografía existente sobre el pishtaco no existen trabajos científicos que den luz sobre el carácter médico-anatómico del proceder del pishtaco con su víctima. El trabajo de Huhle ${ }^{(5)}$ es el único registro que encontramos sugiriendo una vinculación entre el proceso de captura de la víctima, sección respectiva del cuerpo y posterior extirpación de grasa con probables usos médicos, traídos desde Europa ${ }^{(5)}$. Algunos indicios importantes se encuentran también en uno de los primeros trabajos de Molinié sobre el tema ${ }^{(11)}$.

El pishtaco presenta dos modalidades básicas de acción que podríamos definir en función a la muerte inmediata o no de la víctima. En el primer caso, luego de degollar o descuartizar a la víctima, procede a trasladar el cadáver a un paraje solitario o a un lugar especialmente adaptado para ello. Coloca el cadáver colgado del techo boca abajo para que la grasa discurra dentro de un balde o perol. Para acelerar el proceso suele utilizar velas que coloca debajo del cuerpo. Luego dispone de la grasa para la preparación de medicinas, jabones o ungüentos o para su traslado a terceros. En algunas versiones se utiliza también la sangre. No se menciona lo que se realiza con el cuerpo luego de la extracción.

La segunda modalidad es por narcosis ${ }^{(5)}$. El pishtaco sopla un "polvo blanco" sobre la cara de la víctima, la que cae en estado de indefensión y se entrega al trabajo del pishtaco ${ }^{(5)}$. Sobre la composición de este narcótico no se encuentra mención alguna. Entre los aymaras se dice que el llik'ichiri hipnotiza, por eso los pobladores evitan mirarlo a los ojos. Al despertar la persona no presenta dolor, tampoco heridas o cicatrices. La víctima suele 
morir debilitada unos días después. En este método el pishtaco extrae la grasa a través del ombligo, del recto, del abdomen o de la región sacro-lumbar utilizando un instrumento que en razón a las descripciones bien podría tratarse de un inyectable: El Nak'aq propina un golpe suave a los glúteos, para luego introducir la aguja, que está a su vez conectada a un pequeño aparato en donde se recolecta la grasa, y que (el Nak'aq) extrae con gran maestría ${ }^{(5)}$.

Durante el siglo XVII se incrementó en Europa la prescripción de enemas y lavados digestivos. Esto podría explicar en parte la idea de extracción de materia corporal a través del ano (grasa en lugar de heces) que encontramos en algunos relatos, quizá en un intento del poblador local por estructurar mentalmente un proceder incomprensible y desconocido para él, pero que para la época tardía del medioevo era una práctica común.

\section{EL CONTEXTO MÉDICO EN PERÚ DURANTE LA EDAD MEDIA Y EL RENACIMIENTO}

Los Incas alcanzaron un alto nivel de desarrollo en el cuidado público de la salud. Las construcciones de baños públicos con los correspondientes sistemas de canalización así como el eficaz sistema de regulación de costos de vida y programas de ocupación para las personas de la tercera edad y las discapacitadas testifican esto. El ritual anual de la citua ofrecía la oportunidad de limpiar a profundidad las casas ${ }^{(13)}$. El alcoholismo y la drogodependencia eran enérgicamente combatidos ${ }^{(14)}$. Lo más impresionante en materia médica entre los Incas fue el intento de superar la especialización en medicina. El noveno Inca, Pachacutec (1400-1488), estableció como requisito de formación para los futuros médicos y cirujanos, sólidos conocimientos en botánica.

El especialista médico del incanato poseía pocos conocimientos sobre fisiología y patología; las intervenciones quirúrgicas y anatómicas fueron entre ellos una operación empírica en los casos quirúrgicos, y taumatúrgica sortilégica en los de orden médico ${ }^{(15)}$. Los Chimúes y, posteriormente, los Incas realizaban trepanaciones, amputaciones, extracción de tumores e incluso colocación de prótesis ${ }^{(14,15)}$.

En la época pre-Inca la máxima expresión de tecnología médico-quirúrgica la alcanzaron los Moche y los Paracas. Las técnicas de trepanación craneal las aprendieron posteriormente los Incas y otras etnias de la Amazonía oriental donde era común la momificación de las cabezas humanas como trofeos de guerra y protección (15). Bello, señala que no se encuentra dato en las crónicas y relaciones históricas sobre ella entre los Incas; le niega además, el carácter vicarioso y que fuera realizada post mórtem. Se opone a ello el profundo respeto que los indios peruanos tenían por los cadáveres, la falta de amuletos de esa índole en las tumbas y la técnica operatoria revelada estudiando los cráneos perforados ${ }^{(15)}$.

La forma de religiosidad que caracterizó las civilizaciones pre-Incas e Incas, explica la presencia de cabezas momificadas y representaciones escultóricas y pictográficas. Debido a la importancia que se otorgaba a la cabeza como representación de la personalidad, es pertinente deducir el cuidado que se les brindaba. La necesidad de evitar la putrefacción condujo al descubrimiento de sofisticadas técnicas de momificación de los cadáveres, Alcanzando tal perfección, que compitieron en maestría con los egipcios ${ }^{(15)}$. Guamán Poma describe la conservación de los cadáveres entre los Yungas, Chinchaysuyos y Condesuyos que corroboran este cuidado: "[...] Al defunto le destripan y le quitan toda la carne y las tripas y lo meten en una olla nueua y los güesos amortaxa con una manta de algodón y lo cose. $Y$ ciñi con sogas de cabuya que llaman toclla [lazo](...) Luego le pinta con colores de encima al defunto y la carne y el defunto lo mete en su bóbeda y le haze asentar con sus padres y madres y parientes cin allegar a otro ayllo ${ }^{(16)}$.

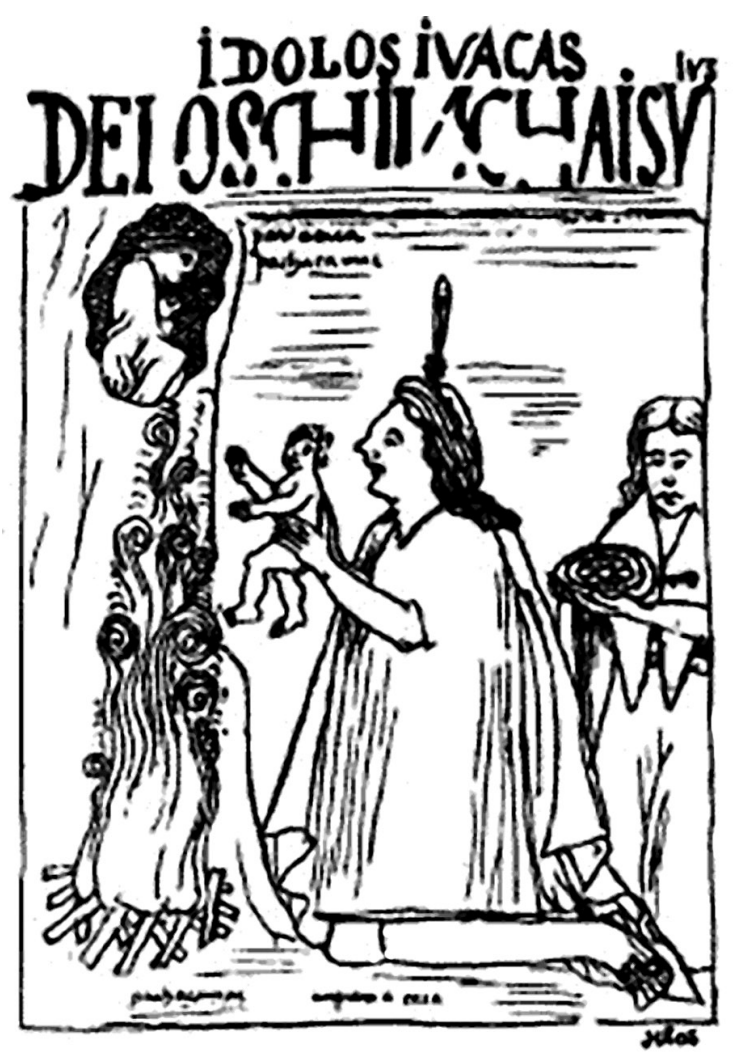

Figura 3. "Ídolos y wakas de los Chinchaysuyo en Pariacaca, Pachacámac creador del universo". Ofreciendo un niño al dios Pachacámac. Figura tomada de Guamán Poma de Ayala 1980 [1615]: Pintura 104, 1: 266 [268]. 
Evidencias etnohistóricas y arqueológicas confirman que los Incas practicaban sacrificios humanos al igual que los Moche (17). La modalidad más extendida en rituales funerarios era la muerte por estrangulamiento. En las ofrendas a dioses específicos o para evitar desastres naturales era común el despeñamiento y el congelamiento (utilizada particularmente en las tumbas de gran altura); el ofrecimiento de vidas humanas estaba reservado para eventos particularmente importantes que no constituían parte del ritual común (Figura 3). El uso de cráneos y otras piezas óseas como huesos y dientes con fines rituales, como trofeos o para fabricar instrumentos musicales han sido también documentados ${ }^{(17)}$.

En las últimas décadas, descubrimientos arqueológicos han otorgado evidencias sobre una larga tradición de sacrificios humanos en culturas anteriores a los Incas. Se encuentra en la figura del oficiante degollador de la cultura Moche (Figura 1) un representante antiguo de lo que, como se ha venido sugiriendo en otros lugares, podría ser el origen del pishtaco. Se ha encontrado numerosos objetos, principalmente cerámicas, que escenifican sacrificios humanos realizados por el sacerdote encargado, las que podrían despertar asociaciones con el proceder de los pishtacos ${ }^{(2)}$. Arguedas ${ }^{(18)}$ señala que la vinculación del ñak'aq con sacrificios y la degollación como oficio religioso es muy antigua e induce a pensar que se trata del mismo personaje.

El degollador debió ser un personaje temido pues no era un sacerdote propiamente dicho sino un individuo diestro en el oficio de seccionar el cuerpo de las víctimas, y deja visible, palpitantes aún, las vísceras, para que el sacerdote iniciara los oficios ${ }^{(3)}$. Este personaje estaba encargado de proveer o sacrificar animales y personas a los templos, a fin de obtener grasa, sangre y carne para llevar a efecto los rituales ${ }^{(12)}$.

El campo de acción del degollador se desarrollaba en el contexto de un calendario ritual político-religioso. La muerte de un elegido, voluntario o no, constituía en sí misma el acto ofrendatorio. Las vísceras y sangre de los sacrificados, principalmente corazón e hígado, eran utilizados en distintas formas (incluídas la toma de sangre) en la ceremonia. Las ofrendas de grasa son siempre de origen animal, principalmente de llama; esta era quemada, enterrada o mezclada con otros elementos como el maíz.

Rivière señala que entre los Aymaras durante ciertos rituales colectivos El oficiante extrae la llika de la llama, se cubre con ella el rostro y la parte de arriba del cuerpo para recibir (katuña) la fuerza vital del animal. Más adelante afirma que La llika es considerada como el único medicamento capáz de curar a la víctima del lik ichiri. Recién extraída de la panza de una llama negra, se la coloca sobre la herida para que restituya la grasa o energía vital al cuerpo debilitado ${ }^{(19)}$. Para todos los casos, la mención es hecha siempre a grasa de origen animal y no humano.

En la figura del pishtaco no encontramos un carácter sagrado, religioso o sacralista. Si analizamos la hipótesis del pishtaco como sacrificador, es necesario determinar a quién se sacrifica, para qué y para quiénes se realiza el ritual. Molinié señala a este respecto, que en el esquema sacrificial del pishtaco (sic) No se conoce ni al uno ni al otro... parece que se debería abandonar la referencia al sacrificio y adoptar la interpretación probablemente exacta del pishtako como una figura del blanco..." (11). Rivière enfatiza que En los rituales tradicionales el uso de la grasa tiene por objeto entrar en comunicación con los Dioses y reforzar los lazos de reciprocidad que unen a éstos con los hombres...no sucede lo mismo con las relaciones establecidas entre el lik'ichiri y los hombres ${ }^{(19)}$. En los relatos sobre el pishtaco la grasa que se extrae es desviada, destinada a su enriquecimiento personal y a un uso exterior.

Por lo expuesto hasta aquí, es difícil vincular al pishtaco con algún personaje de origen andino, pese al halo de ritual que caracteriza la mayoría de versiones recogidas, no existe un carácter "andino" prehispánico de ninguna cultura pre-Inca o Inca asociada clara y directamente con el circuito de extracción de grasa con fines comerciales o usos terapéuticos.

\section{¿QUIÉN ERA ENTONCES ESTE PERSONAJE?}

La pregunta ha sido esbozada anteriormente por otros autores. Molinié señala respecto al pishtaco, que Se trata de un blanco y que hay que considerar que este vampiro andino tiene quizás un homólogo en Europa ${ }^{(11)}$. En otro lugar se dijo De seguro existen conexiones asociativas entre el pishtaco y elementos de las antiguas culturas peruanas. Sin embargo, el primer pishtaco parece haber sido español (5).

\section{EL CONTEXTO DE LA MEDICINA EUROPEA DURANTE LA EDAD MEDIA Y EL RENACIMIENTO}

Para el poblador andino la causa o el origen de la enfermedad se encontraba principalmente en la familia extensa, incluidos en ella, los seres de la naturaleza, las plantas, los animales y en las relaciones sociales inapropiadas o en desequilibrio estructural entre los pobladores mismos, su ayni o comunidad, y la de estos con sus dioses y wakas respectivos. Esta concepción de 
la salud no la compartían los europeos, para quienes el hombre era un ser desvalido y a la vez autónomo, cuya salud no dependía de la calidad de las relaciones que establecía con su familia, la naturaleza o el grupo social. Dentro de una concepción desprovista de un carácter animista u holístico, el hombre europeo se constituía en regidor y destinatario último de su propia salud, con la única posibilidad de pedir ayuda cuando enfermaba a un Dios único, con la intervención de santos específicos ${ }^{(20)}$.

Desde los inicios del cristianismo (300 a.c. - 400 d.c.) hasta fines del renacimiento europeo (siglo XVII), la enfermedad, el dolor y las diversas aflicciones, eran parte de la creación divina de dios. En religiones monoteístas como el judaísmo, el cristianismo y el islam la utilización de medicamentos se prestaba a grandes controversias. En el antiguo y nuevo testamento así como en el Corán se leía la prohibición explícita de utilizar plantas medicinales por considerarse éstas regalos divinos. El uso de ellas equivalía a contradecir la voluntad de Dios o incluso estar en contra del plan divino ${ }^{(20)}$. Surgieron entonces médicos realizando profundas y apasionadas defensio artis medicinae para fundamentar el uso de medicamentos en la medicina, argumentando en ello su origen bíblico y su presencia en escritos religiosos de la época.

La desconfianza frente a la medicina regente de la época era muy grande, ya que al ubicarse su origen en la antigua grecia, era por su naturaleza misma, hereje ${ }^{(20)}$. La medicina de la edad media tenía su centro de conocimiento no en laboratorios u hospitales, sino en bibliotecas. Los médicos eran básicamente filósofos, no científicos en el sentido actual. Con muy pocas evidencias construyeron un sistema altamente especulativo de comprensión y diagnóstico, como el uso de la orina y la toma del pulso para diagnosticar. Mantenida dentro de una tradición clásica, esta medicina carecía de praxis directa con el enfermo.

El área de la medicina medieval que experimentó mayor limitación en su desarrollo fue la cirugía. Con la declaración Ecclesia abhorret a sanguine (la iglesia no derrama sangre) en el Concilio de Tours de 1163 se prohibió el ejercicio de la cirugía por parte de los médicos, quienes en su mayoría eran sacerdotes ${ }^{(14)}$. A fines del siglo XIII e inicios del XIV se dio la separación definitiva entre medicina y cirugía: la primera quedaba reservada a médicos formados en la Academia y la última a la práctica manual de personas escolarizadas como los bañadores y barberos, de cuyo grupo surgen los médicos de heridas o cirujanos, en el nivel más bajo (Figura 4).

Los médicos de heridas o cirujanos se diferenciaban en médico que corta y los llamados incisores, quienes realizaban operaciones de anatomía y apertura de cadáveres.

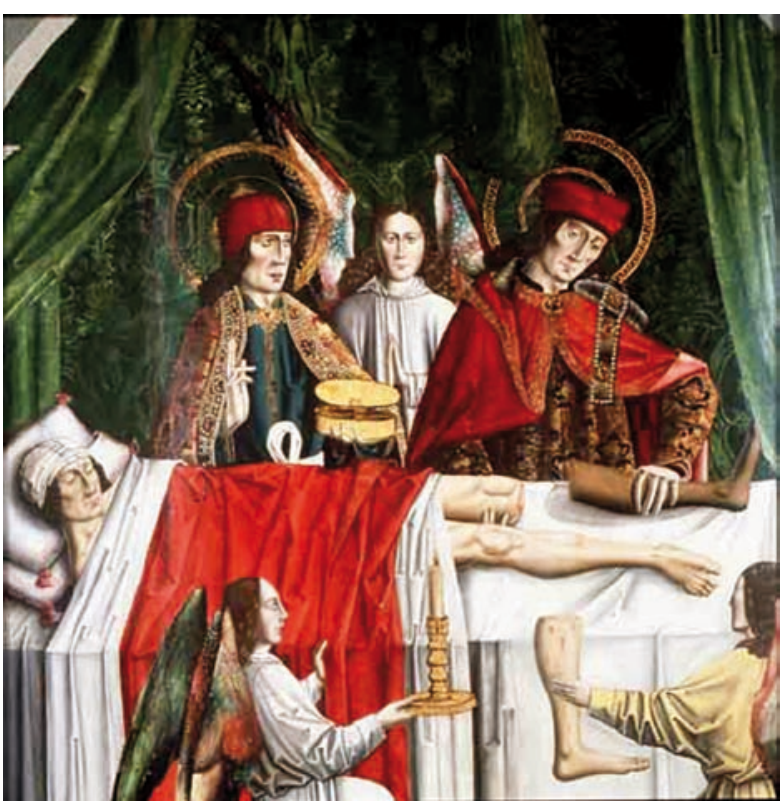

Figura 4. "Cosme y Damián", cuadro atribuído al maestro de los balbasos (1495). Patronos de la medicina europea. En la Legenda Aurea estos hermanos cortaron la pierna quemada de un paciente cristiano y la cambiaron por la de una persona negra fallecida momentos antes (Groebner 2005:5). Foto: Welcome Library.

Los médicos presenciaban las secciones pero no las observaban, sino que trataban de encontrar en ellas evidencias que corroboren lo escrito por Galeno ${ }^{(14)}$. Esta modalidad de secciones se practicó durante 200 años hasta la aparición de la llamada muerte negra, la epidemia de sífilis, que produjo cambios no sólo a nivel del conocimiento médico, sino en los aspectos sociales y económicos en Europa. En Galeno no se mencionaba a la peste y, debido a que el antiguo testamento contenía más información sobre contagios que los clásicos griegos, no es de sorprender que en la edad media tomara de la tradición bíblica explicaciones más plausibles para estas enfermedades masivas y sus diversas formas de contagio ${ }^{(21)}$.

El cambio decisivo contra la tradición galénica llegó a través de Paracelso (1493-1541). En el pensamiento paracelsiano, las experiencias registradas por un simple bañador o una hierbera así como la observación de la naturaleza, eran los elementos principales sobre los cuales debía basarse la medicina, siendo la alquimia y la astrología sus ciencias rectoras ${ }^{(14)}$. Paracelso conceptualizaba al cuerpo humano como un laboratorio químico.

La concepción durante los siglos XV al XVI era que todas las cosas existentes estaban determinadas por fuerzas divinas, satánicas o mágicas. Se consideraba además, que partes específicas del cuerpo humano poseían efectos curativos ${ }^{(22)}$. A mediados del siglo $\mathrm{XV}$ 
se publicó el Picatrix (Piedra de los sabios), un libro que se remonta en contenido hasta la época de Hipócrates. Aquí se encuentran los primeros registros sobre hechizos mágicos que también se utilizaban para el tratamiento de enfermedades.

Los llamados medicamentos de colgado, sobre todo amuletos, debían proteger de enfermedades o desgracias y desempeñaron una función muy importante en el arte de curar. El principio de la signatura de Paracelso, la simbología de colores, la astrología y las creencias místico-religiosas, fueron las razones principales para llevar consigo amuletos. Estos ofrecían defensa y resistencia contra hechizos o eran símbolo de la alianza del individuo con lo divino. El paciente esperaba, a través del simple contacto con el medicamento, no sólo que actúe el contenido, sino que, adicionalmente, se active su poder mágico. Entre los más usados se encontraban ciertas plantas como las raíces de la mandrágora, el Allium victorialis (fam. Liliáceas) y el hyoscyamus, distintos metales, huesos y patas de animales, así como reliquias religiosas.

Los huesos y partes momificadas de santos eran considerados objetos sacrales que producían milagros médicos ${ }^{(10)}$. Si bien la iglesia prohibía expresamente su venta, permitió que pasara a manos de generosos donantes a modo de "obsequio en custodia". La colección del Duque Federico el Sabio, protector posterior de Martín Lutero, contaba con 18970 piezas, alrededor del año $1520^{(10)}$.

Con el inicio de secciones a cuerpos humanos en el siglo XIV, comenzaron también a establecerse reglas para su transporte y disposición; estas no se basaban en los objetivos del trabajo anatómico ni en la organización de la enseñanza en sí, sino en la delimitación cuantitativa de los cuerpos a disposición ${ }^{(23)}$. Paralelamente a esta situación, y desde la introducción del derecho romano en la tradición jurídica europea, el cuerpo estaba descrito y conceptualizado en forma doble: como persona y como cosa. Para que pueda ser traficado o utilizado, este cuerpo debía volverse anónimo y convertido en materia simple: corazón, grasa, hígado, etc.

Hasta comienzos del siglo XVIII, los cuerpos de los ejecutados se utilizaban preferentemente para el estudio anatómico. Estos eran puestos a disposición de los médicos por permiso expreso de las autoridades locales, quienes determinaban a su vez, qué ocurriría con los cuerpos luego de la ejecución. Al tratarse de condenados por un delito o incluso suicidas, no se veía otra utilidad luego de su muerte ${ }^{(24)}$.

Existía pues, un consenso sobre el derecho de las autoridades para disponer de los cuerpos de los difuntos y, finalmente, de cualquiera sea el uso posterior que se haga de ellos. Junto con la posición social y las redes familiares y de parentesco de los difuntos, el nivel económico cumplía una función preponderante. No contar con el dinero suficiente para ser enterrados, era uno de los criterios para ser destinado a las salas de anatomía ${ }^{(24)}$.

\section{FARMACOPEA HUMANI À LA EUROPEA}

El uso de tejidos y fluidos corporales humanos, específicamente con fines médicos, tiene un origen bastante antiguo.

Los egipcios fueron los médicos más cotizados en el cercano oriente antes de la aparición de los médicos griegos. Homero (1000 a.c.) y Herodoto (500 a.c.) no sólo elogiaban a sus médicos, sino a los impresionantes niveles de salud del que gozaba la población. En el papiro Eber se describe, junto con enfermedades como la diabetes y el reumatismo, 876 recetas producidas en base a más de 500 sustancias entre minerales como plomo y sales de carbón, materias vegetales como encina, semillas de aceite de ricino, granada y sustancias animales. Las recetas se preparaban generalmente de una combinación de numerosos derivados, según el método de la polifarmacéutica. Estas incluían elementos de la "farmacia de inmundicias" como orina y excrementos de animales y humanos ${ }^{(14)}$. Es muy probable que se encuentre aquí la mención más remota sobre este tipo de terapia, que bien pudo haberse extendido a través de los griegos hasta la Europa medioeval.

Medicamentos producidos en base a sustancias provenientes de animales (Animalia) tuvieron en la antigüedad una importancia muy grande. El número impresionante de medicamentos hechos en base a sustancias animales fue reduciéndose hasta quedar en el registro sólo unos cuantos, alrededor del mil ochocientos. Pedanios Dioskurides (c. 40- c. 90) describe las propiedades medicinales de cerca de cien animales, además de productos basados en ellos. Hildegard von Bingen menciona en sus escritos cerca de ciento setenta (entre ellas de setenta aves). Su utilización como sustancias de preparación de base para otros medicamentos fue muy extensa, sobre todo durante el siglo XVII, donde alcanzaron su expresión máxima.

A partir del siglo XIV aparece en tratados médicos europeos, la momia (pedazos de cuerpos de momias egipcias) como medicina e ingrediente principal para la preparación de medicamentos. Pairé se ocupa especialmente del polvo de unicornio y la momia, dos de los más famosos medicamentos de su tiempo, poniendo 
en cuestionamiento con evidencias "científicas" la preferencia entre muchos médicos y laicos por estas sustancias (21). A partir del siglo $X V$ se encuentra registrada en inventarios farmacéuticos oficiales (Reglamento farmacéutico de Hamburgo, Alemania, en el siglo XVI y XVII; London Pharmacopoeia del English College of Physicians a fines del siglo XVI). El uso de momia sólo existe registrado en Europa, no así en la antigüedad ni en la medicina de origen árabe ni egipcia. Junto con momia aparece la grasa humana con los mismos fines ${ }^{(10)}$. La momia era el remedio regio preferido por los paracelsianos. Algunas reminiscencias de este uso, como señala Wulle, se encuentran aun durante el siglo XX. En 1908 figuraba por ejemplo en el catálogo de medicamentos de venta de la compañía farmacéutica alemana Merck lo siguiente: Momia egipcia verdadera, aún a disposición, 17.50 marcos reales el kilo ${ }^{(25)}$.

Los medicamentos derivados de sustancias humanas aumentan en proporción durante el siglo XVI, además de momia, se utilizaba grasa, huesos del cráneo, uñas, secreción del oído, saliva, sangre, orina, heces, placenta y leche materna ${ }^{(26)}$. Bajo la denominación de "inmundicia" estaban considerados también los órganos, partes de estos o las excreciones de animales o personas ${ }^{(20)}$. La denominada terapéutica orgánica, que hace referencia a medicamentos que se producen en base a órganos extraídos de animales o humanos o sus secreciones, alcanzó su máximo apogeo alrededor de 1900 y condujo posteriormente al desarrollo de la endocrinología.

El término "canibalismo medicinal" fue desarrollado por la farmacopea moderna para referirse al uso de materia humana en la elaboración de medicamentos y métodos terapéuticos diversos, a partir del renacimiento hasta el siglo XVIII. Para los protestantes paracelsianos de

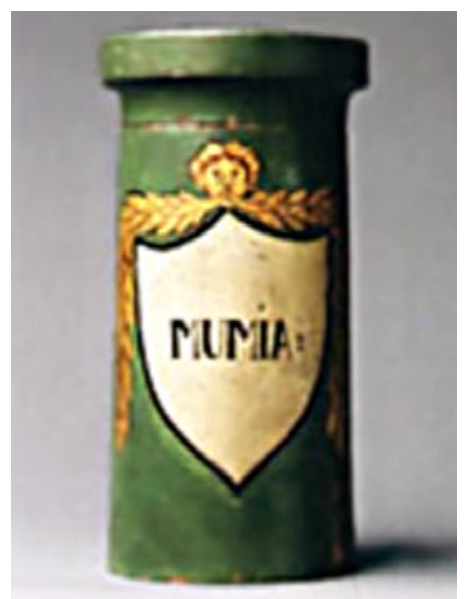

Figura 5. Muestra de mumia (momia) en frasco de madera, siglo XVIII, existente en la colección permanente del Museo de Historia de la Farmacia de Basilea (Suiza). Foto: Internet Site del Museo. la época renacentista, este uso cumplía una función sustituta de la hostia, el transmutado cuerpo y sangre de Cristo ${ }^{(25)}$. La figura definitiva de esta concepción la constituía un "supercuerpo" que impregnó el discurso sobre materia y corporalidad en la edad media: el cuerpo de Cristo, la hostia consagrada de la eucaristía, que se come durante los oficios religiosos para curar y liberar el alma y el cuerpo. El cuerpo humano era considerado como una materia provista de una energia religiosa, lo cual indicaba la ausencia de límites claros entre lo que se constituye como cuerpos que son considerados propios y los que pertenecen al colectivo ${ }^{(27)}$. El debate entre los teóricos de la iglesia católica sobre la ilegitimidad en la compra o venta de personas (carne, sangre) se movía entre la condena teórica y una tolerancia en la práctica de la esclavitud de quienes no eran cristianos.

\section{EL USO DE LA GRASA HUMANA EN LA EDAD MEDIA Y RENACIMIENTO EUROPEOS}

La extracción de grasa de los cuerpos de los asesinados, con fines medicinales, era una práctica de origen europeo. En la historia de la medicina europea se encuentran registros de este uso en forma inequívoca. En el siglo XIV el uso de grasa humana procedente de algún poblador originario de las américas ha sido continuamente registrada, aunque en modo esporádico y en base al registro de cronistas europeos.

En México, durante la época de la invasión española liderada por Hernán Cortéz, se encuentra crónicas que hacen mención directa al uso de la grasa con fines medicinales: Y a lo que después nos dixeron, en aquella batalla les matamos muchos indios, y entre'ellos ocho capitanes muy prinçipales, e hijos de los viejos... Y con el unto del indio, que ya e dicho otras vezes se curaron nuestros soldados, que fueron quinze, y murieron çi[nco] de las heridas; y tanbién se curaron quatro cavallos qu'estavan heridos ${ }^{(28)}$.

El uso de grasa humana con fines medicinales, en especial para curar reuma y escoraciones, se encuentra mencionado en la literatura como parte de algunas prácticas de la medicina popular peruana ${ }^{(29)}$. Esto puede sugerir una incorporación posterior de una práctica de origen europeo, a diferencia de la manera en que lo interpretan otros autores ${ }^{(5)}$. Que Valdizán y Maldonado lo incluyan como una técnica de la medicina popular, encuentra una explicación en la formación académica de médicos en el Perú, la que se inició bajo la administración de la iglesia católica y cuyas fuentes eran europeas. Esta formación académica no consideraba, en lo absoluto, los conocimientos médicos indígenas y su cosmovisión, situación que persiste hasta el presente. 
El interés y valoración de la grasa se mantuvo a través de siglos, especialmente de aquellas procedentes de animales exóticos o de lugares remotos, ya que se les adjudicaba propiedades curativas y fuerzas especiales. En los escritos de Dioskurides se menciona particularmente a la grasa de lobo, de ganso y de pollo como sustancias sumamente efectivas contra dolencias del útero. Menciona también a la grasa de chancho y de oso, así como la de cabra, oveja, ciervo, de ganado vacuno, de toro, pantera y león, entre otras. En la Materia médica se lee: Todas las grasas tienen la propiedad de calentar, relajar y suavizar. La grasa de toro es algo astringente, así como la de ternera; la de león sirve especialmente para reponerse del agotamiento. La grasa de elefante y de ciervo aplicada como ungüento espanta a las serpientes; la grasa de cabra es muy astringente, por eso se la cocina junto con trigo, zumo de uvas y queso para curar la disentería...la grasa de cerdo se presta particularmente bien para dolencias del útero $y$ del recto, también ayuda en el caso de quemaduras con fuego. La grasa de cerdo mezclada con sal brinda calor y suaviza; lavada con vino alivia contra las punzadas; con ceniza o cal quemada sirve para curar edemas, inflamaciones y físulas. La grasa de burro, se dice, hace que las cicatrices adquieran el mismo color de la piel. La grasa de ganso y de pollo es un buen remedio contra dolores femeninos, en el caso de cisuras de los labios, para el cuidado del cutis y dolores de oídos ${ }^{(26)}$.

El uso farmacéutico de la grasa humana se extendió hasta más allá del siglo XVI y XVII, teniendo carácter oficial hasta mediados del siglo XVIII. Andrés Vesalio en su famoso libro de anatomía De humani corporis fabbrica de 1543, menciona en el capítulo referente a la cocción de huesos, que Toda la grasa debe ser extraía y colocada en un recipiente común, con cuidado del pueblo, porque éste usa la grasa para curar sus heridas ${ }^{(10)}$.

En el Dispensatorium pharmaceuticum AustriacoViennense (dispensario farmacéutico oficial establecido por el gobierno de Austria) de 1737 y en sus ediciones posteriores hasta 1770 , encontramos en el listado de medicamentos y sustancias pertenecientes a los aceites especiales, algunos que prescriben la utilización de cráneo y sangre humana, a ser destilados junto con otros materiales como cuerno de ciervo y lombrices. En la clase décimocuarta, que contiene veintiséis compuestos del tipo spiritibus compositis, se encuentra también para el procedimiento de destilación seca cráneo pulverizado y orina humanos con la indicación Que estos procedan de un hombre saludable ${ }^{(30)}$. En un capítulo posterior del mismo Dispensatorium se encuentra preparados compuestos, entre los que resalta uno que utiliza el cráneo de Un hombre fallecido por muerte violenta (sic), que luego de ser limpiado, raspado y triturado, se le pulverizaba junto con agua de flores de mayo, para finalmente ser puesto a proceso de secado ${ }^{(30)}$.

La grasa humana se describe específicamente en la clase décimoséptima, unguentis, donde se detalla la preparación de cincuenta y ocho ungüentos, pomadas y cremas. En la lista de sustancias básicas de preparación de esta clase figuran: grasa de cerdo, mantequilla, grasa de pato, gallinas y gatos, grasa humana, aceite de oliva y aceite de almendras, todos estos utilizados con agregados de cera o sebo. En el procedimiento general de preparación de los ungüentos se cortaban las plantas o raíces escogidas y se las trituraba, para luego ser cocidas en la grasa o aceite hasta que perdieran totalmente el líquido. Esta preparación era seguidamente exprimida y disuelta en el sebo o cera caliente. Al enfriar se le agregaba a esta masa las demás sustancias pulverizadas. Wiltsch señala irónicamente, que para el Windsalbe (ungüento de uso popular muy extendido aún en la actualidad en Austria y Alemania) la farmacopea actual no cuenta más con los veintiséis compuestos originales de su preparación, entre ellos la Fuerza y efectividad de las lombrices y las cuatro grasas de lujo: la de Homo Sapiens, la de perro, la de zorro y la de gato montés ${ }^{(30)}$.

Actualmente se utiliza la grasa de cerdo como elemento básico en la preparación de ungüentos dentro de la Lista Actual de la Farmacopea Alemana ${ }^{(26)}$.

\section{ANATOMÍA DEL PISHTACO}

Desde inicios del siglo XVI hasta fines del siglo XVIII, el control sobre los especialistas médicos no académicos era escaso ${ }^{(31)}$. Entre los diversos especialistas se contaba con el médico de ciudad, el médico de hospital, el médico de la nobleza, el médico de soldados, los miembros de la facultad de medicina, el cirujano o médico de heridas (considerado un trabajador manual), el farmacéutico o boticario, el bañador, el barbero y el hierbero charlatán. Además de estos, figuraba un personaje de sumo interés para nuestro tema; en el inglés y el alemán antiguos se encuentran muy distintos nombres para dicho personaje, variedad toda que denota su controversial labor y la resistencia o precaución de muchos para nombrarlo en público. Se le conocía por los seudónimos de Meister Fix (maestro seguro o fijo), Knüpfauf (ahorcador), Freimann (libertario), Stockwart (vigilante), Peinlein (aplicador de penas, en diminutivo), Angstmann (aterrador), Meister Hämmerlein o little hammer (maestro martillo), Züchtiger (flagelador), o Meister Hans (maestro Juan) ${ }^{(32) . ~ L o s ~}$ denominativos oficiales eran Scharfrichter (ejecutador), Abdecker (desollador), Henker (verdugo) o Nachrichter (mensajero). 


\section{EL VERDUGO: JUSTICIA, MEDICINA Y MAGIA}

Hasta antes del siglo XIII el verdugo no figuraba como un oficio conocido. Según algunas tradiciones orales y escritas, se tenía la creencia que aquel que ejecutara por sí mismo a un condenado, quedaría automáticamente exonerado de la pena y era puesto en libertad. A fines del siglo XIII se empieza a elegir a un miembro del tribunal como ejecutor de la pena. En razón de esta práctica inicial se creó específicamente el oficio de verdugo, con el reconocimiento oficial y la formación correspondientes.

El aspirante a verdugo debía aprender, cómo degollar al condenado con un solo golpe de espada; la manera de romper sus extremidades utilizando la rueda y colgar a los delincuentes de manera que la muerte les sobrevenga lo más rápido posible. También era solicitado para torturar a los sospechosos de delito y dictaminar si estos podían resistir determinadas técnicas de sinceramiento. No se puede descartar su participación en procesos inquisitoriales dada su experticia técnica, a diferencia de médicos con formación académica. En casos de penas de amputación, el verdugo debía cuidar que las heridas cicatrizaran y no produjeran úlceras posteriores. Ser efectivo era una obligación para el verdugo; si fallaba en la aplicación de la pena podía ser linchado por la masa que presenciaba el acto. Es por ello que la formación empezaba a muy temprana edad en su familia, donde el hijo o hija aprendiz practicaba con perros y cabras, diariamente.

Su campo de acción en las ciudades durante el siglo XVI iba más allá de la tortura y la matanza de los condenados. En los llamados permisos de oficio se establecía por escrito y oficialmente, un acuerdo de sus servicios firmado por la autoridad de la ciudad. El verdugo era un funcionario público quien ejercía también otras funciones como la supervisión del estanco de leche y cereales, el desolladero estatal, la limpieza de cloacas y calles de la ciudad, así como el desalojo de mendigos. Meister Hans fue uno de los primeros empleados estatales que existieron y se ocupaba de tareas muy diversas ${ }^{(32)}$.

La manera en que el verdugo llegó a practicar la medicina es algo que aún no se ha investigado convenientemente. Desde el momento en que se tienen registros de actas relativas a sus funciones se le encuentra, sin embargo, claramente asociado con la práctica médica.

Hasta muy entrado el siglo XVIII el verdugo poseía una función reconocida en la medicina popular y era respetado como médico de personas y animales. Lo interesante es que no se le consideraba tan sólo como un empleado del gobierno de la ciudad, sino que era tenido como un servidor social. Aun cuando básicamente tenía contacto con prisioneros a ser interrogados y condenados a muerte, el pueblo lo consultaba como médico. En la mayoría de ciudades de Europa Central él pertenecía al grupo de expertos en curación, junto con los médicos, bañadores, barberos y obstetrices. No es de sorprender la preferencia del pueblo por estos especialistas empíricos, quienes alcanzaron su mayor apogeo durante los siglos XVI y XVII. La mayoría de las personas (casi $80 \%$ de la población) vivía fuera de la ciudad y no tenían mayores posibilidades de contar con atención médica especializada ${ }^{\left({ }^{32}\right)}$. Los bañadores, barberos, verdugos, castradores y charlatanes eran quienes les brindaban atención médica.

Las actividades médicas del verdugo han sido registradas desde inicios del siglo $\mathrm{XV}$, los pacientes le consultaban en caso de enfermedad o dolencias producidas por ulceraciones o heridas ${ }^{(32)}$. Las mujeres también podían asumir el cargo; en esos casos podían ejercer el oficio de verduga sola o en compañía de su esposo. Comúnmente los esposos subían al patíbulo y juntos realizaban el trabajo. Sólo en caso de demandas o problemas legales con relación a la ejecución de un condenado, era el verdugo quien comparecía ante el tribunal y tenía absoluta responsabilidad en el caso.

El campo de ejercicio médico del verdugo cubría básicamente la curación de enfermedades externas $y$ afecciones visibles como luxaciones y roturas de brazos y piernas, amputaciones, heridas producidas por espadas y armas similares, inflamación de extremidades, dolores de articulaciones y coyunturas, morbus Koch o tuberculosis. Para ello utilizaba principalmente ungüentos de diversa composición, aceites de plantas medicinales, vendajes confeccionados por él mismo, vinos de esencias fuertes, ventosas y sangrías, polvo de cuerno de ciervo y hierbas como la valeriana, genciana, enebro, cera y otras específicas de Europa Central (32).

El verdugo compraba la mayoría de sus ingredientes en la farmacia o en establecimientos similares a una drogería ambulante que se encontraban en los mercados. La situación era distinta para el caso de la grasa o manteca humana, conocida también como "grasa de los pobres pecadores", y para la piel humana. La sangre y la grasa de los decapitados la vendían los verdugos o la utilizaban para preparar ungüentos y vendajes, como lo hacía el verdugo de Múnich, quien los distribuía a las farmacias de la ciudad hasta mitad del siglo XVIII (32).

Hasta mediados del siglo XVIII las farmacias en Alemania eran proveídas de sustancias traídas por personas que ejercían funciones médicas menores para la población ${ }^{(20)}$. Este proceso de provisión de sustancias en Europa se caracterizaba por su alta variedad en control, calidad y origen así como en la forma de preparación y acceso. En 
el caso de España y Portugal, a raíz del aislamiento que tuvieran a partir de 1603 bajo el reinado de Felipe II "El Hermoso", los medicamentos de preparación química quedaron bajo el poder de la Inquisición y permanecieron desconocidos hasta la revolución química de Lavoisier, a fines del siglo XVIII ${ }^{(20)}$. Al no tener acceso durante más de dos siglos a métodos químicos más modernos de preparación, se infiere la existencia de un enorme mercado ilegal, en búsqueda constante de sustancias humanas para la preparación de medicamentos utilizando métodos menos convencionales.

La grasa humana era distribuída en medida de una libra (medio kilo) a los boticarios y farmacéuticos europeos hasta mediados del siglo XVIII. Klug señala que esta distribución oficial en boticas sugiere el uso de grasa humana también entre médicos de ciudad y cirujanos ${ }^{(32)}$. Como todo medicamento, se le utilizaba para determinadas enfermedades y dolencias. En 1747 el verdugo Johann Georg Tränckler señalaba en un comunicado a las autoridades locales de Augsburgo (Alemania) que ... Con la mezcla de grasa humana que he aplicado a algunas personas...éstas han encontrado alivio...especialmente las que padecen de bocio (coto, paperas), adelgazamiento de las extremidades $y$, dolores de otras partes del cuerpo... ${ }^{(32)}$.

También la piel de los condenados encontró utilización en este contexto. Con ella se preparaban vendajes que eran cubiertos con un talco de color negro y se utilizaban principalmente para eliminar hinchazones y tumores, como en el caso del bocio o coto o "tumoración en la zona traqueal" (32).

En el caso de la grasa y la piel humana el verdugo tuvo el monopolio absoluto durante el siglo XVI y XVII. Debido a lo establecido en el régimen penitenciario, el verdugo tenía acceso directo inmediato a los cadáveres de los ejecutados, sin embargo, las autoridades debían darle permiso para utilizar estos cuerpos. La municipalidad de Núremberg en Alemania, por ejemplo, accedió a la solicitud del verdugo Hans Schmidt en 1580 y autorizó ...Cortar el cuerpo del decapitado (desollarlo) y tomar de el, todo lo que le sirva de medicamento. Igualmente, en 1613 en Eger (Hungría) se permitió al verdugo de la ciudad ...Sacar la grasa del ejecutado porque con ello se le puede ayudar a muchas personas ${ }^{(32)}$. La venta de grasa y otras partes del cuerpo constituía parte de los ingresos legales del verdugo ${ }^{(10)}$. En caso que no contara con autorización para el aprovechamiento de la piel, grasa y otras partes del cuerpo de los condenados, se le aperturaban procesos judiciales. Éstos han sido documentados en detalle, gracias a lo cual conocemos el proceder del verdugo con el cuerpo. Un interesante y detallado caso es la inspección judicial realizada en 1640 al verdugo Martin Leich- nam en Múnich (Alemania), en este se detalla la técnica de desollamiento utilizada por los hijos del verdugo bajo la dirección paciente y profesional de su madre ${ }^{(32)}$.

La piel y la grasa humana no se consideran hoy en día médicamente efectivas, aun cuando en el sentido médico renacentista lo fueron. En razón a ello, y al proceso de prohibición posterior de su actividad médica para la preparación de medicamentos en base a sustancias y órganos humanos, se le agrupa preferentemente dentro del ámbito de las prácticas médicas "mágicas" (32).

Las actividades del verdugo atribuidas a lo "mágico" se movían dentro de los marcos legales existentes. Lo que se consideraba punible no era en sí la magia que practicaba, sino los hechizos o ars divinandi (adivinación), para los que se sindicó la pena de muerte en la hoguera. Justamente en el campo de la producción y aplicación de medicamentos es que se observa la enorme influencia de los conceptos de naturaleza mágica del neoplato-

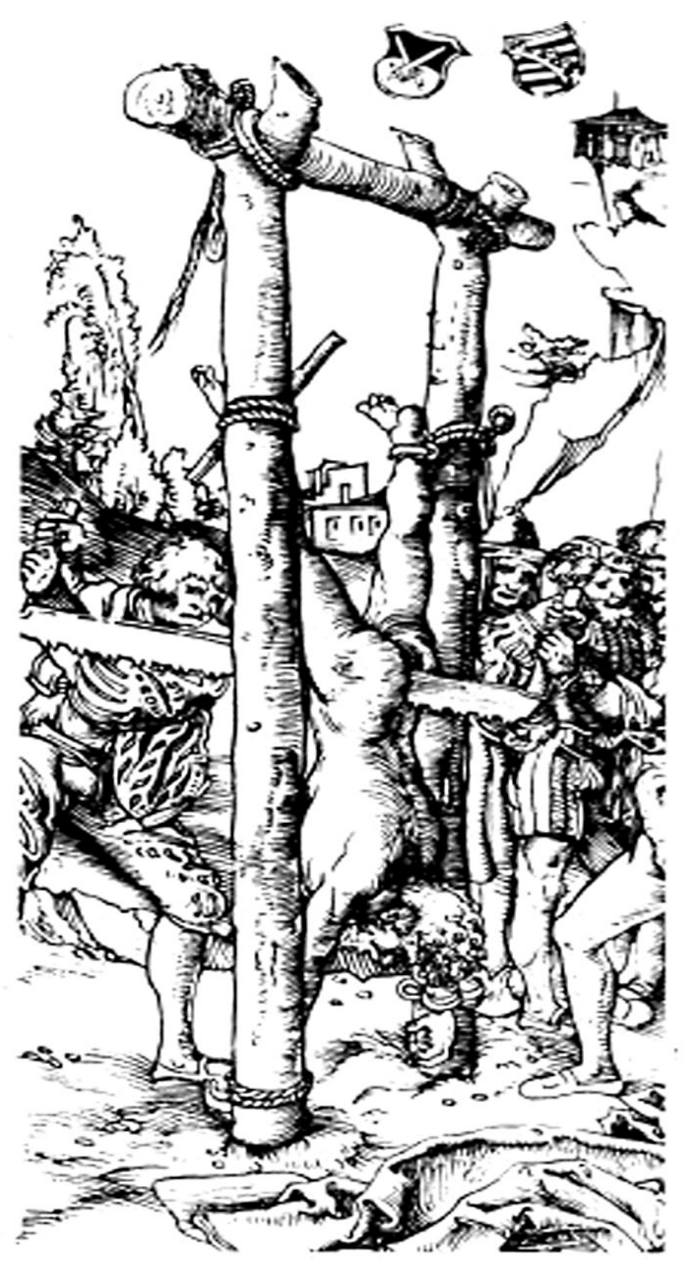

Figura 6. "Der Zersägter" ("el descuartizador") pintura de Lucas Cranach (1539). Foto: Catalogue Raisonné de la Universidad de Leipzig. 
nismo de fines de la antigüedad, sobre la alquimia y los métodos iatroquímicos propios del renacimiento, difundidos por Paracelso. En este contexto, la combinación de hablar al mismo tiempo de usar un objeto, cumplió una función muy importante; en el caso de enfermedades, se decía el conjuro en voz alta al tiempo de ejercer determinadas técnicas de curación, entre las que se contaba la aplicación de medicamentos ${ }^{(20)}$.

Se esperaba del verdugo, por ejemplo, que por su intercesión se encontraran objetos robados y que colaborara con la ubicación e identificación del ladrón. Se le atribuían a su espada fuerzas especiales y nadie se atrevía a tocarla. Se aseguraba que la sed por sangre que poseía esa espada era insaciable; si un condenado recibía la absolución, era necesario ofrendarle una gallina negra en su lugar, como medida de "apaciguamiento" (32). Astillas del bastón del verdugo, así como trozos de la soga con la que ahorcaba a los condenados eran prendas con mucha demanda entre sus clientes. Se pensaba que la mandrágora (radix victorialis), una planta muy cotizada para la confección de amuletos, crecía especialmente bajo la horca ${ }^{(32)}$.

A la piel de los ejecutados confeccionada como amuleto o prenda de vestir se le atribuían fuerzas corporales y mágicas excepcionales ${ }^{(33)}$. Igual o mayor reputación gozaban los huesos. A las manos de ladrones o sus pulgares se le describía como muy efectivas para asegurar un robo exitoso; si eran enterradas bajo un establo garantizaban que los caballos permanezcan sanos así como fomentaban la producción de leche de las vacas. La cabeza, los sesos y el cráneo de los estrangulados brindaban alivio a muchas dolencias. La sangre tibia tomada inmediatamente después de la decapitación de un condenado curaba la epilepsia; un pedazo de tela manchada en esta sangre y colocada en la vitrina o el mostrador de una tienda brindaba al comerciante o vendedor pringües ganancias. El verdugo construyó, sin lugar a dudas, un lucrativo negocio paralelo con estos amuletos y talismanes.

En el área de la producción cosmética, y entre la cantidad de preparados de moda cosméticos estudiados por Simon (Hickel, p. 317) ${ }^{(20)}$ figuran las pomadas y ungüentos de manzana debido a sus efectos "positivos". Productores de perfumes de la tardía edad media originarios del sur de Europa, crearon ungüentos de una característica altamente cremosa a partir de diversos tipos de grasa. Estos ungüentos estaban emparentados con los llamados pomander que eran pequeños contenedores de perfume que las mujeres del renacimiento colgaban de sus cuellos. Junto con clavos de olor de manzana y canela, estas esencias eran mezcladas con grasa, la que al iniciar el proceso de putrefacción, permitía la liberación de su esencia aromática. En Francia la palabra pomata se cambio a pommade (ungüento, pomada), de ahí el origen del nombre. En ninguna de estas fuentes se especifica, sin embargo, si la grasa era de origen humano, pero tampoco se asevera lo contrario.

A partir de la segunda mitad del siglo XVII los servicios de magia del verdugo fueron reduciéndose en forma paulatina, prevaleciendo en primer plano su función de médico veterinario y consejero. Él permaneció, no obstante para la sociedad de su época, como un agente de salud efectivo y eficiente, que supo hacer de su trabajo una medicina bastante lucrativa.

\section{CONSIDERACIONES FINALES}

Basándonos en las evidencias científicas encontradas, podemos formular un intento de explicación desde el punto de vista de la medicina antropológica para el origen del pishtaco.

Como ha sido anotado históricamente, las primeras tripulaciones españolas bajo las órdenes de Francisco Pizarro que arribaron al imperio Inca estaban conformadas básicamente por soldados y miembros de la Iglesia. Dada la composición social de este grupo, se podría pensar que los usos médicos que se hacía de la grasa humana en aquélla época eran de su más pleno y directo conocimiento. Recordemos que muchos de los sacerdotes europeos de la época tenían formación médica y actuaban también como cirujanos militares en el caso que no hubiera un cirujano de heridas presente en la expedición. Por otro lado, los soldados españoles estaban constantemente expuestos a contagios y enfermedades en el "nuevo mundo" así como a ser heridos, requerían entonces, el tratamiento conocido por ellos y correspondiente a su tiempo y uso. Es muy difícil pensar que en los primeros momentos los españoles hicieran uso inmediato de la medicina local. Al ser el primer grupo europeo en entrar en contacto con los nativos del Tawantinsuyo, no es difícil suponer una transmisión más o menos directa de informaciones sobre estas técnicas terapéuticas.

Es muy probable también que durante la conquista se desarrollaran percepciones específicas que favorecieron la aparición de un personaje como el pishtaco con los evidentes atributos médicos correspondientes. La concepción queel poblador tawantinsuyanotenía respecto a sus propios sacerdotes y el haber presenciado la quema de sus muertos por parte de los sacerdotes españoles durante los procesos de extirpación de idolatrías, se constituyeron muy posiblemente en el prolegómeno más inmediato a este fenómeno. Recordemos que los Incas 
sometían a sus muertos a procesos de momificación, así que es también probable que con ayuda de los soldados algunos sacerdotes o médicos guardaran parte de estas reliquias como un sustituto de la momia medicinal para ser usados in situ o ser enviados a la península ibérica. En el caso de los caídos en combate o resistencia, es probable también que los pobladores presenciaran -ya sea por observación directa o referencia tangencial- la extracción o el uso de la grasa de estos cuerpos que han podido hacer los soldados o cirujanos militares y la manera en que la aplicaban para curar sus heridas. Esto se corrobora en cierta medida con el primer levantamiento en Perú contra la dominación española en 1571, el Taki Onqoy, desatada justamente por los rumores entre la población respecto al uso de la grasa de los indígenas muertos a ser envíada a Europa. Las historias sobre el pishtaco surgidas en Latinoamérica inducen a pensar que se sabía con exactitud lo que los europeos hacían con sus cuerpos.

Para el poblador andino estaba sobreentendido que el rango social atribuido a un soldado, era ostensiblemente menor al de un sacerdote. En su concepción, los soldados actuaban en razón a las indicaciones y órdenes de los clérigos. El sacerdote inca posee un poder real, tangible y directo sobre los elementos que constituyen el mundo andino. Tiene la capacidad para controlar situaciones sociales cuyo desequilibrio afecta los estados de salud y generan enfermedad. Para el poblador del incanato, el sacerdote tenía, además de las funciones espirituales y rituales, las médicas, algo que para ellos constituía una unidad indivisible. Muchos de los sacerdotes europeos les hablaban en el idioma oficial del imperio, el quechua, lo que les confería un halo adicional de autoridad. Tanto el sacerdote inca como el europeo "sana", "cura" e "interviene" en el orden de las cosas. Es por ello probable que la identificación más antigua del pishtaco como un sacerdote se extendió hasta muy entrada la etapa republicana en el Perú.

Parte central de los relatos referidos al pishtaco mencionan el uso de grasa humana con fines terapéuticos o comerciales. La existencia de medicamentos, principalmente ungüentos, preparados en base a esta "grasa de los pobres pecadores" se encuentra registrada en los dispensatorios farmacéuticos europeos así como su modo de obtención, preparación, distribución y venta hasta inicios del siglo XVIII. Junto con ella, encontramos también toda una lista de sustancias derivadas del cuerpo humano como órganos diversos, uñas, cráneo, huesos, sangre, placenta y orina principalmente, que servían también para la fabricación de medicamentos en forma oficial.

Hemos expuesto en detalle las evidencias que nos permiten afirman la existencia de un pishtaco original europeo, el carácter mismo del personaje, el oficio que ejercía, sus instrumentos, la mercantilización de las sustancias y órganos de los muertos a su mano constituían parte de su trabajo habitual y poseía un mercado seguro y oficial para la compra de dichos productos. Esta práctica estaba absolutamente normada, gozaba de carácter legal y se encontraba inserta en un sistema de atención y cuidado de la salud que estaba en concordancia con la concepción médica y religiosa de la época en relación al cuerpo humano, la salud, la enfermedad y su terapéutica.

En los registros consultados encontramos un discurso pleno de ambivalencia frente al valor y uso del cuerpo en sentido religioso, médico y filosófico. El hecho de sanar o curar implicaba al mismo tiempo la enfermedad o muerte del otro, o constituían éstos su precedente ineludible. El elemento adicional de carácter netamente extractivo, sin ningún beneficio o reposición para la víctima o sus familiares sugiere una presencia inmanente de la cultura occidental, que se caracteriza históricamente por su modalidad desvinculante y no circulante en el tejido social.

Al hablar sobre el pishtaco nos enfrentamos al carácter de un personaje presente en el imaginario andino, pero cuyo origen se ubica dentro de la visión europea mágicomédica de clara tradición renacentista.

Algunos autores hablan de las "narrativas de protesta" para referirse a estas creencias y relatos en la manera en que el discurso se articula en aquellas narraciones donde el cuerpo es utilizado. Las formas de violencia externa y dominación que emergen de este discurso se trabajan a nivel social, buscando revertir de alguna manera, cuando menos a nivel del discurso, la situación de opresión y explotación recurrente. En las historias más actuales sobre robo de órganos se reflejan también las diferencias en las condiciones de vida a las que están expensas estos cuerpos, las que están determinadas por su posición relativa en el mundo de carácter social y económico, cuando no cultural.

Para el discurso médico, dichas observaciones son de singular importancia en la medida que estas creencias evidencian actitudes específicas de los pobladores frente a los agentes de salud del estado y al sistema de atención de salud en general. El miedo, rechazo o desconfianza frente a ellos tiene una base histórica cierta. Estudios posteriores sobre este hecho cultural basados en evidencias científicas pueden determinar su valor interpretativo y metodológico real, de manera que forme parte de una reflexión crítica y respetuosa frente al poblador andino y sea considerada dentro de los procesos de decisión y las políticas oficiales de "adecuación intercultural" en los servicios de salud en el Perú. 


\section{AGRADECIMIENTOS}

A mi asesor el Dr. Prof. Armin Prinz, director del Unit Ethnomedicine and International Health de la Universidad de Medicina de Viena por la orientación bibliográfica sobre el tema. A las antropólogas Lupe Camino, Morayma Montibeller y Natalia Picaroni por sus valiosos comentarios y sugerencias para este artículo.

\section{Conflictos de Interés}

La autora declara no tener conflictos de interés en la ejecución y publicación de este artículo.

\section{REFERENCIAS BIBLIOGRÁFICAS}

1. Morote E. El degollador Nakaq. Tradición. 1952; 11: 67-91.

2. Hocquenghem A. Iconografía Mochica. Lima: Pontificia Universidad Católica del Perú; 1987.

3. Ansión J. Pishtacos de verdugos a sacaojos. Lima: Tarea; 1989.

4. Kapsoli W. Los Pishtacos: degolladores o degollados. Bull Inst Fr Études Andines. 1991; 20(1): 61-77.

5. Huhle R. Pistaco - Der Herr des Fettes: Funktion und Wandel des Bildes vom fremden Herrn bei den "indios" in den Zentralanden. Iberoamericana. 1990; (40/41): 96-125.

6. Montibeller M. Relatos sobre pishtacos. Lima: s/p; 1996.

7. Arguedas J. Folklore del Valle del Mantaro. Rev Folklore Americano. 1953; 1(1): 101-298.

8. Molina C. Relación de las fábulas y ritos de los Incas [1573]. En: Romero C, editor. Colección de libros y documentos referentes a la historia del Perú I. Lima: Sanmartí y CA; 1916.

9. Palma R. Tradiciones Peruanas. Palma E, editora. Madrid: Aguilar; 1964.

10. Groebner V. Ausgeschlachtet und verkauft: Der menschliche Körper als Ware - Aktualität und Geschichte. Baz kulturmagazin. 2008; 13(12): 4-5.

11. Molinié-Fioravanti A. Sebo bueno, indio muerto: la estructura de una creencia andina. Bull Inst fr études andines. 1991; 20 (1): 79-92.

12. Celestino $\mathbf{O}$. Transformaciones religiosas en los Andes peruanos, 1. Ciclos míticos y rituales [página de Internet]. Granada: Gaceta de Antropología; 1997. [Acceso en Enero de 2010]. Disponible en: http://www.ugr.es/ pwlac/ G13_06Olinda_Celestino.html.

13. Baudin L. So lebten die Inkas. Stuttgart: Deutsche VerlagsAnstalt; 1957.

14. Ackerknecht E. Geschichte der Medizin. $2^{\mathrm{a}}$ ed. Stuttgart: Enke; 1977.

15. Bello E. La cirugía del cráneo entre los antiguos pobladores del Perú. Revista Médica Latino-Americana. 1925; 10 (117).

16. Guaman Poma de Ayala F. El primer nueva crónica y Buen gobierno [1615]. 3 volúmenes. México: Siglo Veintiuno; 1980.
17. Verano J. The physical evidence of human sacrifice in ancient Peru. En: Benson E, Cook A, editores. Ritual Sacrifice in ancient Peru. Austin: University of Texas Press; 2001. p. 165-184.

18. Arguedas J. Relatos completos. Buenos Aires: Losada; 1974.

19. Rivière G. Lik'ichiri y Kharisiri: A propósito de las representaciones del "otro" en la sociedad aymara. Bull Inst Fr Études Andines. 1991; 20(1): 23-40.

20. Hickel E. Die arzneimittel in der geschichte: trost und täuschung- heil und handelsware. Nordhausen: Traugott Bautz; 2008.

21. Pairé A. Discours d'Ambroise Paré: Alcauoir, De la mumie; De la licorne; Des venins; De la peste. Avec une table des plus notables matières contenues esdits discours. Paris: Gabriel Buon; 1582.

22. Groebner V. Fleisch und Blut, Haut und Haar. Vermarktete Körperteile historisch. Mittelweg 36. 2008; 16: 58-73.

23. Bretschneider H. Der Streit um die Vivisektion im 19. Jahrhundert. Stuttgart: Gustav Fischer Verlag; 1962.

24. StükenbrockK. DerzerstückteCörper:ZurSozialgeschichte der anatomischen Sektionen in der frühen Neuzeit (16501800). Stuttgart: Steiner; 2001.

25. Gordon-Grube K. Evidence of medicinal cannibalism in puritan New England: "Mummy" and related remedies in Edward Taylor's "Dispensatory". Early American Literature. 1993; 28(3): 185-221.

26. Wulle S. Bilsenkraut und Bibergeil: Zur Entwicklung des Arzneischatzes. Braunschweig: Universitätsbibliothek Braunschweig; 1999.

27. Groebner V. Körper auf dem Markt: Söldner, Organhandel und die Geschichte der Körpergeschichte. Mittelweg 36. 2005; 6: 69-84.

28. Diaz del Castillo B. Historia verdadera de la Conquista de la Nueva España [1575, 1632]. Introducción y notas de Joaquín Ramirez Cabañas. México D.F.: Porrúa, Colección Sepan Cuántos, 5; 1974.

29. Valdizan H, Maldonado A. La medicina popular Peruana. Lima: Torres Aguirre; 1922.

30. Wiltsch A. Das Dispensatorium pharmaceuticum Austriaco-Viennense, nach d. Ausgaben von 1737 u. 1770 besprochen. Wels: Sonderdruck aus dem Jahrbuch des städt. Museums zu Wels; 1935.

31. García Ballester L. Ethical problems in the relationship between doctors and patients in fourteenth-century Spain: On Christian and Jewish Practitioners. En: Kottek S, García Ballester L, editores. Medicine and medical ethics in medieval and early modern spain. Jerusalem: The magnes Press \& the Hebrew University; 1996, p.11-32.

32. Bahn H. Harnglas, Kräuter, Menschenfett. Engelsberg in Bretten: Bretten Sparkasse Kraichgau; 2002.

33. Hansmann L, Kriss-Rettenbeck, L. Amulett, Magie, Talismann. München: Neudruck Hamburg; 1977.

Correspondencia: Rosario de Pribyl

Dirección: Apostelgasse 35/11 A-1030 Viena, Austria.

Teléfono: (43) 6769236901

Correo electrónico: rosario.pribyl@chello.at 